\title{
Hereditary Cancer-Associated Mutations in Women Diagnosed with Two Primary Cancers: An Opportunity to Identify Hereditary Cancer Syndromes after the First Cancer Diagnosis
}

\author{
Jennifer Saam Kelsey Moyes Michelle Landon Kayon Williams \\ Rajesh R. Kaldate Christopher Arnell Richard Wenstrup
}

Myriad Genetic Laboratories, Inc., Salt Lake City, Utah, USA

\author{
Key Words \\ Genetic testing · Neoplasms · Second primary cancer . \\ Hereditary breast and ovarian cancer syndrome . \\ Colorectal neoplasms · Hereditary nonpolyposis . \\ Neoplastic syndromes
}

\begin{abstract}
Objectives: Patients with hereditary cancer syndromes are at high risk for a second primary cancer. Early identification of these patients after an initial cancer diagnosis is the key to implementing cancer risk-reducing strategies. Methods: A commercial laboratory database was searched for women with a history of both breast and ovarian or colorectal and endometrial cancer who underwent genetic testing for hereditary breast and ovarian cancer (HBOC) or Lynch syndrome (LS). Results: Among women with both breast and ovarian cancer, $22.4 \%(2,237 / 9,982)$ had a BRCA1 or BRCA2 mutation. Among women with both colorectal and ovarian cancer, $28.1 \%$ (264/941) had a mutation associated with LS. In $66.6 \%$ of BRCA1 or BRCA2 mutation carriers and in $58.3 \%$ of LS mutation carriers, $>5$ years passed between the cancer diagnoses. Of patients with HBOC and LS, 56 and 65.2\%, respectively, met the National Comprehensive Cancer Network guidelines for hereditary cancer testing after their initial diagnosis based on their personal cancer history alone.
\end{abstract}

\begin{tabular}{ll}
\hline KARGER 125/\% & $\begin{array}{l}\text { (1) 2014 S. Karger AG, Basel } \\
0030-2414 / 14 / 0884-0226 \$ 39.50 / 0 \quad \text { Karger }\end{array}$ \\
E-Mail karger@karger.com & $\begin{array}{l}\text { This is an Open Access article licensed under the terms of the } \\
\text { www.karger.com/ocl }\end{array}$ \\
& $\begin{array}{l}\text { Creative Commons Attribution-NonCommercial 3.0 Un- } \\
\text { ported license (CC BY-NC) (www.karger.com/OA-license), } \\
\text { applicable to the online version of the article only. Distribu- } \\
\text { tion permitted for non-commercial purposes only. }\end{array}$
\end{tabular}

Conclusions: A substantial number of women tested for LS or $\mathrm{HBOC}$ after being diagnosed with two successive primary cancers were diagnosed with a hereditary cancer syndrome. In many cases, the time interval between the diagnoses was long enough to allow for the implementation of surveillance and/or prophylactic measures.

(c) 2014 S. Karger AG, Basel

\section{Introduction}

Approximately $5-10 \%$ of all cancers occur in patients with hereditary cancer syndromes, over 50 of which have been described [1]. Two of the most common hereditary cancer syndromes are hereditary breast and ovarian cancer (HBOC) and Lynch syndrome (LS; also known as hereditary nonpolyposis colorectal cancer). Patients with hereditary cancer syndromes are at risk for additional malignancies following their first diagnosis [1], and, therefore, the identification of these patients is important in order to minimize their risk for a second cancer diagnosis.

It is estimated that $5-10 \%$ of all breast and ovarian cancers result from heritable mutations [2]. HBOC is caused by the most commonly inherited mutations, namely those in the breast cancer, early-onset 1 (BRCA1) and 2

Dr. Jennifer Saam

Myriad Genetic Laboratories, Inc

320 Wakara Way

Salt Lake City, UT 84108 (USA)

E-Mail jsaam@myriad.com 
(BRCA2) genes [1]. Patients with HBOC are frequently diagnosed with ovarian cancer, with up to $10 \%$ of all ovarian cancers resulting from mutations in $B R C A 1$ or $B R C A 2$ $[3,4]$. Furthermore, there is an elevated risk for pancreatic cancer, prostate cancer, and melanoma $[5,6]$.

The risk for breast cancer in $B R C A 1$ or $B R C A 2$ mutation carriers is up to $87 \%$ at 70 years of age [7], while the risk for nonmutation carriers is only $8 \%$ [8]. Patients with HBOC are often diagnosed at a younger age than those with sporadic breast cancer, with the average age at diagnosis being 52 years of age $[9,10]$. The average age of patients diagnosed with sporadic breast and ovarian cancer is 61 and 63 years of age in the general population, respectively [11].

LS results primarily from mutations in DNA mismatch repair genes, including $M L H 1, M S H 2, M S H 6$, and PMS2 [12]. It accounts for $2-4 \%$ of all cases of colorectal cancer $[13,14]$ and for the majority of inherited endometrial cancers [15-17]. Several studies have indicated that women with LS may have an equal risk for colorectal and endometrial cancer and that patients may present first with either cancer [18-20]. These patients are also at an elevated risk for ovarian, gastric, hepatobiliary tract, and ureter cancer, as well as sebaceous adenoma or carcinoma $[21,22]$. The lifetime risk for colorectal or endometrial cancer in the general population is 2 and $1.5 \%$ [23], respectively, as compared to $82 \%$ [19] and $71 \%$ [24] in patients with LS. Patients with LS are also more often diagnosed with cancer at an earlier age than those with sporadic colorectal or endometrial cancer. The average age of onset for colorectal cancer in patients with LS is 58 years [11], while the average age of onset for sporadic colorectal or endometrial cancer in those patients is 69 and 62 years, respectively [11].

Patients with hereditary cancer syndromes are at a much higher risk for being diagnosed with a second cancer than the general population. Such cancers can be synchronous or metachronous and in the same organ or in a distant organ. The risk for contralateral breast cancer in $B R C A 1$ or BRCA2 mutation carriers is up to $64 \%$ at 70 years of age [25], compared with $2-11 \%$ for the general population [26]. Furthermore, the 10-year risk for contralateral breast cancer after a first diagnosis is $43.4 \%$ in $B R C A 1$ mutation carriers [27] and an estimated $6 \%$ in the general population [28]. Patients diagnosed with cancer at a young age, as commonly occurs in $\mathrm{HBOC}$, are at the highest risk for developing contralateral breast cancer [3, 29]. In addition to the risk for contralateral breast cancer, $B R C A 1$ or $B R C A 2$ mutation carriers also have an elevated risk for ovarian cancer $[3,4]$. A large study estimated that, in patients with $\mathrm{HBOC}$, the risk for developing ovarian cancer following primary breast cancer is between 6.8 and $12.7 \%$, depending on mutation status, with $B R C A 1$ carriers having the highest risk [30].

Patients with LS are also at risk for second primary cancer. A study in women diagnosed with two primary cancers found that $49 \%$ presented first with colorectal cancer and 51\% with endometrial cancer [18]. In women presenting with colorectal cancer, the 20 -year risk for endometrial cancer may be as high as $48 \%$ [31].

The current National Comprehensive Cancer Network (NCCN) guidelines recommend molecular genetic testing in individuals with a personal and/or family history consistent with HBOC or LS $[3,32]$. With regard to personal cancer history, it is recommended that all patients with ovarian cancer should be tested for $B R C A 1$ or $B R C A 2$ mutations, in addition to those diagnosed with breast cancer before the age of 45 [3]. Genetic testing for LS is suggested for patients diagnosed with colorectal cancer or endometrial cancer before the age of 50 [32]. Newly developed risk assessment algorithms that are able to calculate the likelihood of hereditary cancer based on personal and family history are currently in use [33]. Starting in 2014, NCCN guidelines recommend screening for LS in patients scoring $\geq 5 \%$ risk on mutation models such as the PREMM $M_{1,2,6}$, which evaluates the risk for carrying a mutation in $M L H 1, M S H 2$, and MSH6 [32, 33].

This retrospective analysis focused on women diagnosed with at least two primary cancers who were tested for hereditary cancer mutations in order to determine the prevalence of mutation carriers and to examine the time interval between the two diagnoses. In addition, the number of women who would meet the current NCCN guidelines for genetic testing after their first cancer diagnosis was determined.

\section{Materials and Methods}

To collect patient records, a commercial laboratory database was queried for women with a personal history of both breast and ovarian cancer (HBOC query) or both colorectal and endometrial cancer (LS query) who underwent genetic testing. Patient information was obtained from the health care provider on the test order form. Information from test request forms included personal and family history, type of cancer, and age at cancer diagnoses. All patients included in the HBOC query were tested between September 2006 and October 2013 and had full sequencing of BRCA1 and $B R C A 2$, and some patients also had large rearrangement testing of $B R C A 1$ and BRCA2. The LS query included all patients who had full sequencing of MSH6 in addition to full sequencing and large rearrangement testing of $M L H 1$ and $M S H 2$ between May 2008 and 


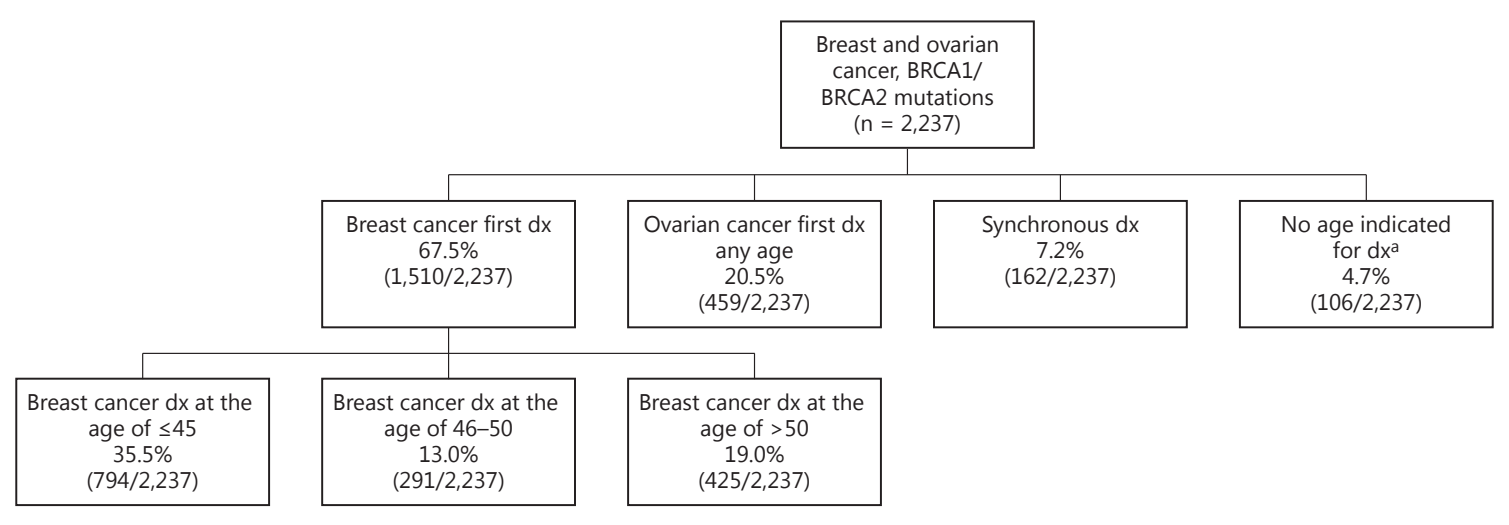

Fig. 1. Incidence of breast and ovarian cancer in patients with HBOC. Patients with $B R C A 1 / 2$ mutations were segregated based on the first cancer diagnosis. Patients presenting with breast cancer were further stratified based on age at diagnosis. $\mathrm{dx}=\mathrm{Diagnosis} .{ }^{\mathrm{a}} \mathrm{No}$ age indicated for at least one cancer diagnosis.

October 2013. Some patients also had large rearrangement testing of MSH6 and EPCAM as well as full sequencing and large rearrangement testing of PMS2. Candidates were excluded from this retrospective study if they (1) were tested only for the Ashkenazi Jewish founder mutations in BRCA1 or BRCA2, (2) had singlegene testing for LS or HBOC, or (3) were tested for a previously identified familial HBOC or LS mutation. Patients with a second breast cancer or a second colorectal cancer were not queried due to the difficulty of distinguishing between a second primary cancer and a recurrence.

Mutation prevalence was established and patients carrying HBOC- or LS-associated mutations were stratified based on age at earliest cancer diagnosis. The time that elapsed between the first and the second diagnosis was established. The percentage of patients who would have met the 2012 or 2013 NCCN testing guidelines after the initial cancer diagnosis was also determined using patient cancer history. Patient family cancer history was not included in this analysis.

\section{Results}

\section{HBOC Query}

This analysis identified 9,982 patients diagnosed with both primary breast and ovarian cancer and 2,237 women (22.4\%) with a mutation in either $B R C A 1$ or $B R C A 2$ or in both $B R C A 1$ and $B R C A 2$ (fig. 1). The majority had mutations in $B R C A 1$ (fig. 2). Patients presenting with a first malignancy between 30 and 39 years of age were most likely to carry a mutation in BRCA1 or BRCA2 (35.8\%), followed by those diagnosed between 40 and 49 years of age $(30.6 \%$; table 1$)$.

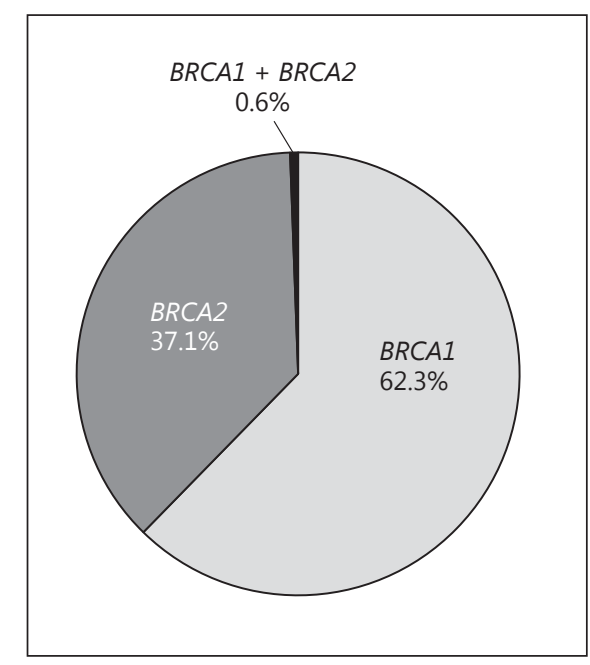

Fig. 2. Mutation distribution in patients with HBOC. Patients diagnosed with breast and ovarian cancer underwent genetic testing for mutations in BRCA1 and BRCA2.

Of the BRCA1 or BRCA2 mutation carriers, $67.5 \%$ were diagnosed first with breast cancer, $20.5 \%$ were diagnosed first with ovarian cancer, and 7.2\% were diagnosed concurrently with both breast and ovarian cancer. Nearly $60 \%$ of BRCA1 or BRCA2 mutation carriers $(1,323$ of 2,237 patients) were diagnosed with either breast or ovarian cancer before the age of 50 . Furthermore, over $50 \%$ of $B R C A 1$ or $B R C A 2$ patients with sentinel breast cancer were diagnosed before the age of 45 (794 of 1,510 pa- 


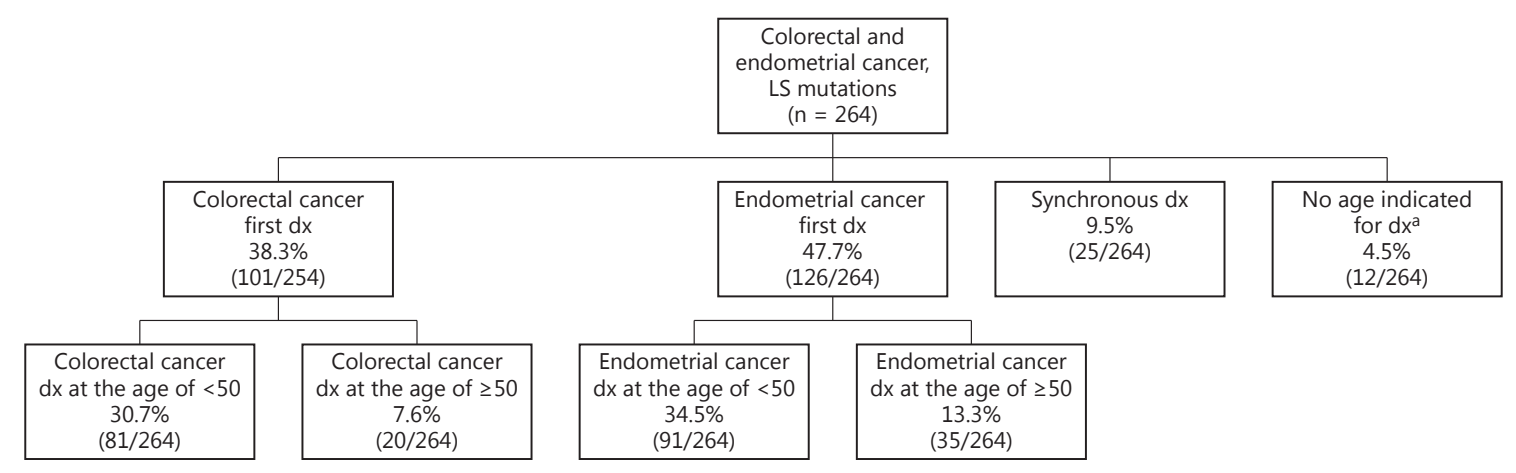

Fig. 3. Incidence of colorectal and endometrial cancer in patients with LS. Patients with LS-associated mutations were segregated based on the first cancer diagnosis. Patients presenting with either colorectal cancer or endometrial cancer were further stratified based on age at diagnosis. $\mathrm{dx}=$ Diagnosis. ${ }^{\mathrm{a}}$ No age indicated for at least one cancer diagnosis.

Table 1. Age breakdown of patients with both breast and ovarian cancer by age at first cancer diagnosis

\begin{tabular}{lccc}
\hline $\begin{array}{l}\text { Age at first } \\
\text { diagnosis }\end{array}$ & \multicolumn{3}{l}{ Breast and ovarian cancer } \\
\cline { 2 - 4 } & $\begin{array}{l}\text { patient } \\
\text { count, } \mathrm{n}\end{array}$ & $\begin{array}{l}\text { BRCA-positive } \\
\text { patients, } \mathrm{n}\end{array}$ & $\begin{array}{c}\text { positive } \\
\text { rate, } \%\end{array}$ \\
\hline $0-9$ & 3 & 0 & 0 \\
$10-19$ & 47 & 3 & 6.4 \\
$20-29$ & 428 & 84 & 19.6 \\
$30-39$ & 1,211 & 433 & 35.8 \\
$40-49$ & 2,627 & 803 & 30.6 \\
$50-59$ & 2,747 & 610 & 22.2 \\
$60-69$ & 1,756 & 211 & 12 \\
$70-79$ & 717 & 55 & 7.7 \\
$80-89$ & 150 & 1 & 0.7 \\
$\geq 90$ & 2 & 1 & $50^{\mathrm{a}}$ \\
Not specified & & & \\
\hline Total & 294 & 36 & 12.2 \\
\hline
\end{tabular}

a Artificially high positive rate due to small sample size.

${ }^{b}$ No age indicated for at least one cancer diagnosis.

tients). $21.4 \%$ of patients presented with a second cancer within 5 years of the first diagnosis. For $66.6 \%$ of patients with HBOC, more than 5 years passed between the first and the second diagnosis (table 2).

\section{LS Query}

This query identified 941 patients with both colorectal and endometrial cancer, $264(28.1 \%)$ of whom had a mutation in MLH1, MSH2, MSH6, PMS2, or MSH2 and EPCAM (fig. 3). The distribution of these mutations is shown in
Table 2. Interval between the first and the second cancer diagnosis in patients with $\mathrm{HBOC}$

\begin{tabular}{lc}
\hline $\begin{array}{l}\text { Time between first and second } \\
\text { diagnosis, years }\end{array}$ & Frequency, $\mathrm{n}(\%)$ \\
\hline 1 & $84(3.8)$ \\
$2-5$ & $395(17.7)$ \\
$6-10$ & $486(21.7)$ \\
$11-15$ & $384(17.2)$ \\
$16-20$ & $297(13.3)$ \\
$>20$ & $323(14.4)$ \\
Not specified ${ }^{a}$ & $106(4.7)$ \\
Synchronous diagnosis & $162(7.2)$ \\
\hline Total & 2,237 \\
\hline \multicolumn{2}{c}{ a No age indicated for at least one cancer diagnosis. } \\
\hline
\end{tabular}

figure 4. Nearly half of all patients diagnosed with a first primary cancer between 40 and 49 years of age carried a hereditary LS-associated mutation (121 of 259; table 3 ).

Within the LS cohort, $69.7 \%$ of patients were diagnosed with colorectal or endometrial cancer before the age of 50 (184 of 264). The presenting cancer was colorectal in $38.3 \%$ of patients and endometrial in $47.7 \%$ of patients, and $9.5 \%$ were diagnosed concurrently with colorectal and endometrial cancer (fig. 4). Of patients presenting with colorectal cancer, $80.2 \%$ (81 of 101) were diagnosed before the age of 50 . More than 5 years passed between the first and the second diagnosis in $58.3 \%$ of patients (table 4 ), while $27.7 \%$ of patients were diagnosed with a second cancer within 5 years of the original diagnosis. 


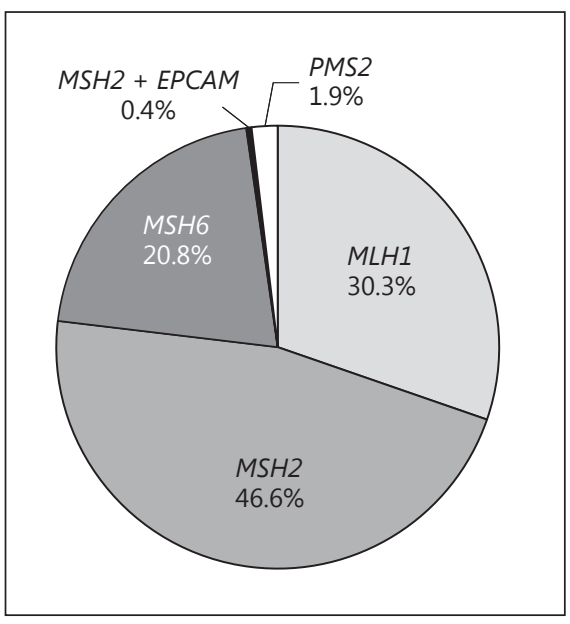

Fig. 4. Mutation distribution in LS mutation carriers with two cancers. Patients diagnosed with colorectal and endometrial cancer underwent genetic testing for mutations in $M L H 1, M S H 2, M S H 6$, PMS2, and MSH2/EPCAM.

\section{Comparison with Current Guidelines}

Based on the current NCCN guidelines, $56 \%$ of the patients identified with mutations in BRCA1 or BRCA2 who were diagnosed with both breast and ovarian cancer would have met the criteria for genetic testing after their first cancer based on either the presence of ovarian or breast cancer before the age of 45 (35.5\% diagnosed with breast cancer before the age of 45 , and $20.5 \%$ diagnosed with ovarian cancer at any age). Considering the overall population of patients with both breast and ovarian cancer, $12.5 \%$ had a mutation and met the criteria after the first cancer diagnosis. Of the patients identified as LS mutation carriers, $65.2 \%$ would have met the current NCCN criteria for genetic testing based on the age of diagnosis of the initial cancer diagnosis $30.7 \%$ diagnosed with colorectal cancer and $34.5 \%$ with endometrial cancer before the age of 50). For this cohort of women with colorectal and endometrial cancer, $18.3 \%$ had an LS mutation and met the NCCN criteria for testing after their initial cancer diagnosis.

\section{Discussion}

This retrospective analysis demonstrates that a substantial number of women who present with a second primary breast, ovarian, colorectal, or endometrial cancer carry a genetic mutation associated with a heritable cancer syndrome. Furthermore, patients who met the
Table 3. Age breakdown of patients with both colorectal and endometrial cancer by age at first cancer diagnosis

\begin{tabular}{lccc}
\hline \multirow{2}{*}{$\begin{array}{l}\text { Age at first } \\
\text { diagnosis }\end{array}$} & \multicolumn{3}{l}{ Colorectal and endometrial cancer } \\
\cline { 2 - 4 } & $\begin{array}{l}\text { patient } \\
\text { count, } \mathrm{n}\end{array}$ & $\begin{array}{l}\text { LS-positive } \\
\text { patients, } \mathrm{n}\end{array}$ & $\begin{array}{l}\text { positive } \\
\text { rate, } \%\end{array}$ \\
\hline $10-19$ & 4 & 1 & 25 \\
$20-29$ & 55 & 16 & 29.1 \\
$30-39$ & 133 & 46 & 34.6 \\
$40-49$ & 259 & 121 & 46.7 \\
$50-59$ & 261 & 63 & 24.1 \\
$60-69$ & 140 & 9 & 6.4 \\
$70-79$ & 57 & 3 & 5.3 \\
$80-89$ & 10 & 0 & 0 \\
Not specified & 22 & 5 & 22.7 \\
\hline Total & 941 & 264 & 28.1 \\
\hline
\end{tabular}

${ }^{a}$ No age indicated for at least one cancer diagnosis.

Table 4. Interval between first and second cancer diagnoses in patients with LS

\begin{tabular}{ll}
\hline $\begin{array}{l}\text { Years between first and } \\
\text { second diagnoses }\end{array}$ & Frequency, n (\%) \\
\hline 1 & $20(7.6)$ \\
$2-5$ & $53(20.1)$ \\
$6-10$ & $57(21.6)$ \\
$11-15$ & $52(19.7)$ \\
$16-20$ & $23(8.7)$ \\
$>20$ & $22(8.3)$ \\
Not specified & $12(4.5)$ \\
Synchronous diagnosis & $25(9.5)$ \\
\hline Total & 264 \\
\hline
\end{tabular}

${ }^{a}$ No age indicated for at least one cancer diagnosis.

current NCCN guidelines for HBOC [3] or LS [32] genetic testing after their initial cancer diagnosis make up a large portion of all patients within these cohorts. Of 9,982 patients with breast and ovarian cancer tested for $B R C A 1$ or $B R C A 2,12.5 \%$ had a mutation and met the current NCCN criteria after their first cancer diagnosis. Of 941 patients with endometrial and colorectal cancer tested for LN, $18.3 \%$ had a mutation and met the current NCCN criteria after their first cancer diagnosis. This study highlights the importance of identifying appropriate patients for genetic testing, as they may be able to 
take measures to either reduce their risk for a second cancer or increase the likelihood of early detection of a second malignancy. The interval times between the first and the second cancer diagnosis in this study suggest that there is time to initiate surveillance or prophylactic measures.

Many of the women in the present analysis were diagnosed with breast cancer after the age of 45 but they may still have qualified for testing based on family history or triple negative status. It is especially important to survey women with HBOC after a breast cancer diagnosis because many of them will survive their breast cancer but remain at risk for ovarian cancer, which has a higher mortality rate. Furthermore, current screening protocols for ovarian cancer, including transvaginal ultrasound and monitoring of serum CA-125 concentration, lack sensitivity and specificity and do not reduce the overall risk for mortality [34]. Bilateral salpingo-oophorectomy has been well established as a successful method for the prevention of ovarian and fallopian tube cancers in BRCA1 and $B R C A 2$ carriers. In addition to significantly reducing the risk for ovarian cancer [35], preventive oophorectomy may also reduce the risk for breast cancer by up to $56 \%$ in $B R C A 1$ mutation carriers and $46 \%$ in BRCA2 carriers [36]. Patients with HBOC often undergo bilateral mastectomy as treatment for their breast cancer as it significantly reduces the risk for a second breast cancer [37]. This cohort also demonstrates a group of patients who could have benefited from prophylactic mastectomy after an ovarian cancer diagnosis as they survived ovarian cancer for a period of time that also put them at risk for breast cancer.

Surveillance and prophylactic surgery are the standard of care in patients with LS as they may reduce the associated morbidity and mortality $[38,39]$. Regular colonoscopic screening every 1-3 years may decrease the risk for colorectal cancer by over $60 \%$ [38]. It is important that screening takes place at more frequent intervals in patients with LS because the progression to carcinoma is much more rapid, occurring in $<5$ years, while sporadic cancer usually develops over a period of 5-10 years [ 1 , 40]. Results from the current study reinforce the importance of regular colonoscopic screening as $47.7 \%$ of patients in this study presented first with endometrial cancer, making them vulnerable to a later diagnosis of colorectal cancer. Furthermore, it reinforces the role of gynecologists and gynecologic oncologists in supporting genetic testing for patients with endometrial cancer, as nearly half of all patients with LS present first with a gynecologic cancer.

Hereditary Cancer-Associated Mutations in Women with Two Primary Cancers
In this study, at least 5 years passed between the first and the second diagnosis in the majority of patients with a hereditary cancer syndrome. Of note, a 5-year remission is a common oncology mark after which a patient is considered cancer-free. The data presented here suggest that patients with hereditary cancer syndromes are still vulnerable to a second diagnosis after the 5-year mark. As noted above, this allows time to employ risk-reducing strategies, including increased surveillance or prophylactic surgery.

As all patient information was gathered from the test request form, the current study is reliant on the ordering physician for correct information regarding personal history, age of onset, and diagnosis. Family history was not factored into the analysis, which limited the number of patients who met the NCCN guidelines after their first cancer. Taking a conservative approach and excluding these patients suggests that the rate of second primary cancer in patients with HBOC or LS in clinical practice may actually be higher than reported in this study.

Despite the establishment of recommended guidelines for genetic testing by the NCCN and the American Society of Clinical Oncologists (ASCO), in many cases, patients are not tested due to a lack of awareness of hereditary cancer syndromes or a perceived difficulty of referral for genetic testing. Early identification of patients with hereditary cancer syndromes benefits all involved with the care and treatment of these patients. As recommended by the ASCO, taking a thorough cancer family history at the first oncology visit is the first step in identifying at-risk patients $[41,42]$. A recent study evaluating the ASCO Quality Oncology Practice Initiative demonstrated that physicians participating in the program consistently obtain some first- and seconddegree family histories from their patients, although a complete family cancer history is collected in less than $40 \%$ of patients. While $25.6 \%$ of patients were referred for genetic testing following an evaluation of the family history, only about $50 \%$ of patients were correctly identified as candidates for genetic testing [42]. The ASCO expert statement on the collection and use of a cancer family history for oncology providers highlights the importance of identifying patients with hereditary cancer syndromes so their risk for a second primary cancer can be taken into account during the development of a management plan [41].

In conclusion, the results presented here reinforce the importance of identifying patients who are at risk for having hereditary cancer syndromes. In certain cas- 
es, increased surveillance may lead to the early identification of a second cancer. When surveillance is not appropriate or effective, as in ovarian cancer, prophylactic surgery following the first cancer may significantly reduce the risk for a second cancer. As genetic testing is part of the standard of care with support of the NCCN guidelines, there is an opportunity to develop best practices to ensure that all patients who meet the guidelines are offered testing to identify additional at-risk patients.

\section{Acknowledgements}

This research was funded by Myriad Genetics, Inc. We thank the clinicians and patients who have made this work possible. Medical writing assistance was provided by Deborah Jensen, $\mathrm{PhD}$ (Precept Medical Communications) through funding by Myriad Genetics, Inc.

\section{Disclosure Statement}

All authors are salaried employees of Myriad Genetic Laboratories, Inc.

\section{References}

1 Nagy R, Sweet K, Eng C: Highly penetrant hereditary cancer syndromes. Oncogene 2004; 23:6445-6470.

2 National Cancer Institute: Genetics of Breast and Ovarian Cancer (PDG). http://www.cancer.gov/cancertopics/pdq/genetics/breastand-ovarian/HealthProfessional/page1/AllPages (pp 1-219; accessed March 2014).

3 National Comprehensive Cancer Networks: NCCN clinical practice guidelines in oncology (NCCN Guidelines): genetic/familial highrisk assessment: breast and ovarian. http:// www.nccn.org/professionals/physician_gls/ pdf/genetics_screening.pdf (accessed March 2014).

4 Pal T, Permuth-Wey J, Betts JA, et al: BRCA1 and BRCA2 mutations account for a large proportion of ovarian carcinoma cases. Cancer 2005;104:2807-2816.

5 The Breast Cancer Linkage Consortium: Cancer risks in BRCA2 mutation carriers. J Natl Cancer Inst 1999;91:1310-1316.

-6 Levy-Lahad E, Friedman E: Cancer risks among BRCA1 and BRCA2 mutation carriers. Br J Cancer 2007;96:11-15.

7 Antoniou A, Pharoah PD, Narod S, et al: Average risks of breast and ovarian cancer associated with BRCA1 or BRCA2 mutations detected in case series unselected for family history: a combined analysis of 22 studies. Am J Hum Genet 2003;72:1117-1130.

8 Statistical Research and Applications Branch NCI: DevCan: Probability of Developing or Dying of Cancer Software, Version 6.0. 2005. http://srab.cancer.gov/devcan (accessed May 2011).

9 Lynch HT, Watson P, Lynch JF, Conway TA, Fili M: Hereditary ovarian cancer. Heterogeneity in age at onset. Cancer 1993;71:573-581.

10 Domchek SM, Jhaveri K, Patil S, et al: Risk of metachronous breast cancer after BRCA mutation-associated ovarian cancer. Cancer 2013;119:1344-1348
11 Howlader N, Noone AM, Krapcho M, et al: SEER Cancer Statistics Review, 1975-2010. National Cancer Institute, Bethesda. http:// seer.cancer.gov/csr/1975_2010 (based on November 2012 SEER data submission; accessed April 2014).

12 Boland CR, Goel A: Microsatellite instability in colorectal cancer. Gastroenterology 2010; 138:2073-2087.

13 Hampel H, Frankel WL, Martin E, et al: Screening for the Lynch syndrome (hereditary nonpolyposis colorectal cancer). N Engl J Med 2005;352:1851-1860.

14 Hampel H, Frankel WL, Martin E, et al: Feasibility of screening for Lynch syndrome among patients with colorectal cancer. J Clin Oncol 2008;26:5783-5788.

15 Watson P, Vasen HF, Mecklin JP, Jarvinen H, Lynch HT: The risk of endometrial cancer in hereditary nonpolyposis colorectal cancer. Am J Med 1994;96:516-520.

16 Watson P, Lynch HT: Extracolonic cancer in hereditary nonpolyposis colorectal cancer. Cancer 1993; 71:677-685.

17 Meyer LA, Broaddus RR, Lu KH: Endometrial cancer and Lynch syndrome: clinical and pathologic considerations. Cancer Control 2009;16:14-22.

18 Lu KH, Dinh M, Kohlmann W, et al: Gynecologic cancer as a 'sentinel cancer' for women with hereditary nonpolyposis colorectal cancer syndrome. Obstet Gynecol 2005; 105:569574.

19 Aarnio M, Sankila R, Pukkala E, et al: Cancer risk in mutation carriers of DNA-mismatchrepair genes. Int J Cancer 1999;81:214-218.

20 Dunlop MG, Farrington SM, Carothers AD, et al: Cancer risk associated with germline DNA mismatch repair gene mutations. Hum Mol Genet 1997;6:105-110.

21 Watson P, Vasen HF, Mecklin JP, et al: The risk of extra-colonic, extra-endometrial cancer in the Lynch syndrome. Int J Cancer 2008; 123:444-449.
22 Barrow E, Robinson L, Alduaij W, et al: Cumulative lifetime incidence of extracolonic cancers in Lynch syndrome: a report of 121 families with proven mutations. Clin Genet 2009;75:141-149.

23 National Cancer Institute: Surveillance, Epidemiology, and End Results (SEER). 2007. http://seer.cancer.gov/statistics/ (accessed May 2014).

24 Hendriks YM, Wagner A, Morreau H, et al: Cancer risk in hereditary nonpolyposis colorectal cancer due to MSH6 mutations: impact on counseling and surveillance. Gastroenterology 2004;127:17-25.

25 Ford D, Easton DF, Bishop DT, Narod SA, Goldgar DE: Risks of cancer in BRCA1-mutation carriers. Breast Cancer Linkage Consortium. Lancet 1994;343:692-695.

26 Chen Y, Thompson W, Semenciw R, Mao Y: Epidemiology of contralateral breast cancer. Cancer Epidemiol Biomarkers Prev 1999;8: 855-861.

27 Metcalfe K, Lynch HT, Ghadirian P, et al: Contralateral breast cancer in BRCA1 and BRCA2 mutation carriers. J Clin Oncol 2004; 22:2328-2335.

28 Gao X, Fisher SG, Emami B: Risk of second primary cancer in the contralateral breast in women treated for early-stage breast cancer: a population-based study. Int J Radiat Oncol Biol Phys 2003;56:1038-1045.

29 Graeser MK, Engel C, Rhiem K, et al: Contralateral breast cancer risk in BRCA1 and BRCA2 mutation carriers. J Clin Oncol 2009; 27:5887-5892.

30 Metcalfe KA, Lynch HT, Ghadirian P, et al: The risk of ovarian cancer after breast cancer in BRCA1 and BRCA2 carriers. Gynecol Oncol 2005;96:222-226.

31 Win AK, Lindor NM, Winship I, et al: Risks of colorectal and other cancers after endometrial cancer for women with Lynch syndrome. J Natl Cancer Inst 2013;105:274-279. 
32 National Comprehensive Cancer Networks: NCCN clinical practice guidelines in oncology (NCCN Guidelines): genetic/familial highrisk assessment: colorectal. http://www.nccn. org/professionals/physician_gls/pdf/genetics_colon.pdf (accessed March 2014).

-33 Kastrinos F, Steyerberg EW, Mercado R, et al: The PREMM $(1,2,6)$ model predicts risk of MLH1, MSH2, and MSH6 germline mutations based on cancer history. Gastroenterology 2011;140:73-81.

34 Buys SS, Partridge E, Black A, et al: Effect of screening on ovarian cancer mortality: the Prostate, Lung, Colorectal and Ovarian (PLCO) Cancer Screening Randomized Controlled Trial. JAMA 2011;305:2295-2303.

-35 Kauff ND, Satagopan JM, Robson ME, et al: Risk-reducing salpingo-oophorectomy in women with a BRCA1 or BRCA2 mutation. N Engl J Med 2002;346:1609-1615.
36 Eisen A, Lubinski J, Klijn J, et al: Breast cancer risk following bilateral oophorectomy in BRCA1 and BRCA2 mutation carriers: an international case-control study. J Clin Oncol 2005;23:7491-7496.

37 Rebbeck TR, Friebel T, Lynch HT, et al: Bilateral prophylactic mastectomy reduces breast cancer risk in BRCA1 and BRCA2 mutation carriers: the PROSE Study Group. J Clin Oncol 2004;22:1055-1062.

38 Jarvinen HJ, Aarnio M, Mustonen H, et al: Controlled 15-year trial on screening for colorectal cancer in families with hereditary nonpolyposis colorectal cancer. Gastroenterology 2000;118:829-834.
39 Schmeler KM, Lynch HT, Chen LM, et al: Prophylactic surgery to reduce the risk of gynecologic cancers in the Lynch syndrome. $\mathrm{N}$ Engl J Med 2006;354:261-269.

-40 Edelstein DL, Axilbund J, Baxter M, et al: Rapid development of colorectal neoplasia in patients with Lynch syndrome. Clin Gastroenterol Hepatol 2011;9:340-343.

$41 \mathrm{Lu} \mathrm{KH}$, Wood ME, Daniels M, et al: American Society of Clinical Oncology Expert Statement: collection and use of a cancer family history for oncology providers. J Clin Oncol 2014;32:833-840.

42 Wood ME, Kadlubek P, Pham TH, et al: Quality of cancer family history and referral for genetic counseling and testing among oncology practices: a pilot test of quality measures as part of the American Society of Clinical Oncology Quality Oncology Practice Initiative. J Clin Oncol 2014;32:824-829. 